\title{
Role of knowledge management practices for escalating universities’ performance in Pakistan
}

\author{
Raja Ahmed Jamil ${ }^{\mathrm{a} *}$ and Muhammad Saeed Lodhi ${ }^{\mathrm{b}}$
}

${ }^{a}$ Lecturer, Department of Management Sciences, University of Haripur, Pakistan

${ }^{b}$ Assistant Professor, Department of Management Sciences, COMSATS Institute of Information Technology, Abbottabad, Pakistan

C H RO N I C L E

\begin{tabular}{l}
\hline Article history: \\
Received March 25, 2015 \\
Received in revised format June \\
102015 \\
Accepted August 62015 \\
Available online \\
August 62015 \\
\hline Keywords: \\
Knowledge management \\
processes \\
Knowledge management \\
infrastructure \\
Information Sharing, universities' \\
performance \\
Pakistan
\end{tabular}

\begin{abstract}
A B S T R A C T
The purpose of this study is to examine the role of knowledge management practices in enhancing performance of universities, specifically in the context of Pakistan. A convenient sample of 450 employees from the universities all over the Pakistan was taken for the study. Exploratory factor analysis was performed to identify the elements of knowledge management and linear regression analysis was performed to test the hypotheses presented in the study. This study measures the moderating role of technology in the knowledge management framework. Furthermore, it relied on R\&D, employee commitment and industry linkages to construct universities' performance. The results revealed that knowledge management process and knowledge management infrastructure (HR and culture) are significant predictors of the performance of universities. It was also found that technology moderates the relationship of knowledge management dimensions and universities' performance. The study highlighted that with proper attention towards knowledge management infrastructure, knowledge management processes and technology, universities can outperform their competitors.
\end{abstract}

\section{Introduction}

Dawn of twenty first century has witnessed a tremendous shift from the economy of materials and production to the economy of information and knowledge. Knowledge has become an integral economic resource of modern times and in fact the only source to comparative advantage (Drucker, 1993). As a consequence, many organizations whether small or large, have realized the potential of knowledge management (KM) and they are investing rigorously in the knowledge management practices. The aim of knowledge management is to enhance the performance of an organization through proper utilization of knowledge resource. It comprises the process of generating, capturing and applying the knowledge to enhance an organizational performance (Nonaka, 1994). There has been a recent surge to the application of knowledge management practices in the long run success of organizations in corporate sector. Gold et al. (2001) studied the relation of KM infrastructure

\footnotetext{
* Corresponding author. Tel: +923008118557

E-mail address: rathore_ahmad@yahoo.com (R. A. Jamil) 
capabilities and knowledge management processes capabilities with the organizational effectiveness. Lee and Choi (2003) studied how an organizational creativity is a consequence of knowledge management practices. Quink (2008) investigated the relation of KM infrastructure, KM processes and the effectiveness of nonprofit organizations. Mills and Smith (2011) examined the impact of knowledge management resources on the organizational performance. Chang and Chuang (2011) empirically researched the role of KM infrastructure capability and business strategy on the performance of a firm. Meihami and Meihami (2014) while studying the manufacturing companies found that knowledge management is a way to gain competitive advantage in firms. Betz et al. (2014a) argued that government and university policies are needed for helical innovation model to work in the developing economies like Asia.

These above and other studies in corporate sector suggest that KM process and KM infrastructure leads to the success of an organization. However, research on the application of KM practices is still in naïve stages in the education sector specifically to the context of Pakistan. Although studies have been conducted in other cultures e.g. while studying the application of knowledge management in universities research of Singapore, Loh, Tang, Menkhoff, Chay, and Evers (2003) found that creation and maintenance of relevant knowledge repositories, improving knowledge access and environment, and valuing knowledge can benefit higher education institutions. Similarly, Shoham and Perry (2009) stressed the importance of knowledge management for the technological and organizational change in Israeli universities.

The above discussion recognizes the importance of KM practices in universities and findings from the success of KM practices in corporate sector; we opted to study the impact of KM practices on universities' performance in Pakistan. The model is derived from earlier studies on knowledge management in corporate sector, which identifies how KM infrastructure and KM processes lead to the enhanced performance of universities in Pakistan. Furthermore, the model also tests the moderating role played by technology on the relation of KM elements and universities’ performance.

\section{Literature review}

\subsection{Knowledge Management Infrastructure}

\section{a. Human resources}

In current era, the power of a company (economic or production) resides within the intellectual assets rather than the tangible assets (Quinn, 1992). Human resources are one of the most influential drivers of knowledge management. In order to achieve organizational goals, Soliman and Spooner (2000) mentioned that a culture which allows free flow of knowledge within the organization must be leveraged. This culture can be created through proper human resource management. Lee et al. (2013) aimed to analyze the relationship between KM infrastructures, knowledge process capabilities, creative organizational learning, and organizational performance. Along with other factors, they concluded that top management support leads to organizational performance. When employees are rewarded for knowledge management practices, it positively impacts the knowledge management performance (Yu et al., 2004). When organizations motivate employees for knowledge sharing and link rewards directly with the knowledge sharing, than better knowledge management performance is a consequence (Wu, 2004).

\section{b. Knowledge management culture}

Knowledge culture is defined as a type of organizational culture that influences the creating, sharing and making full use of the knowledge for the prosperity of organization (Oliver and Kandadi, 2006). 
King (2008) referred to the fact that culture is considerably related to knowledge sharing behaviors of individual personnel, groups and overall organizations. It is the culture that determines which knowledge to be shared, with whom to share and when it should be shared. King (2006) argued that the motivation of people to share their indigenous knowledge with others, especially when they are not well acquainted to each other is very important. Attitude towards learning, flexibility and intention to share information influences the knowledge management performance significantly (Yu et al., 2004). Thus in order to manage the knowledge effectively in an organization, a knowledge culture must be fostered (Gholipour et al., 2010). Pandey and Dutta (2013) examined the role of knowledge infrastructure capability in knowledge management practices within an organization and suggested that organizational structure plays a facilitating and steering role in developing the culture of knowledge. According to Betz (2014b, p. 761). The problem of proper control in society is a complicated issue. It is complicated by the fact that three different types of control exist in a society: control in sociotechnical systems, control in managed systems, and control in self-organizing systems.

Organizational culture is considered to be the biggest obstacle in the way of effective knowledge management. To manage knowledge more efficiently, an organization must shape its culture more effectively (Davenport and Klahr, 1998; Leonard, 1995). Thus the interaction between individual employees in an organization is a key to innovation (Leonard \& Sensiper, 1998). Often the new ideas are created courtesy to the dialogue between individuals in an organization. Hence, formal as well as informal interaction among the employees should be encouraged which will allow for the sharing of ideas and opinions (O'Dell \& Grayson, 1998). Interaction among the individuals becomes significant when there is an intention to transmit tacit knowledge between individuals or to convert that tacit knowledge into explicit form. This knowledge will ultimately be transferred to organizational level (Nonaka \& Takeuchi, 1995). It was suggested that individual should be able to organize their own knowledge and they should have the ability to apply their knowledge for the solution of prevailing organizational problems (O'Dell \& Grayson, 1998).

Many scholars have pointed out the corporate vision is an imperative element of the culture (Leonard, 1995). The overall vision of an organization states a clear goal of organization and ignites the mandatory actions in the organization to achieve those goals (Nonaka and Takeuchi, 1995). A vision incorporates two things: first it shows the desired future direction of the organization and secondly it shows the organizational values. A well-articulated and well communicated vision can be utilized to develop involvement and contribution among the employees (O'Dell \& Grayson, 1998). Vision and the corporate values determine the knowledge that is required by the organization and the knowledge related activates accepted by the organization (Leonard, 1995; Levinthal \& March, 1993). Hence the clearly stated visions foster the knowledge management behaviors in the organization (Krogh, 1998). In conclusion, the focus in the vision statements should be put on those components of the organization that promote the knowledge management processes to occur.

\subsection{Knowledge management processes}

\section{a. Acquisition}

Knowledge acquisition can be organizational as well as individual. Liao et al. (2009) defined organizational knowledge acquisition as gathering knowledge from the external environment and molding it to be useful for the organization. Thus it involves extraction, interpretation, and transfer of knowledge for the enhancement of knowledge that already resides with organization. However, the individual knowledge acquisition comprises three different ways to gather knowledge: obtaining from the knowledge repository within the organization, learning from other individuals, and learning from experience (Ryu et al., 2005). Knowledge within an organization usually resides within the individual's memory (Bock et al., 2005). Thus acquiring of knowledge within an organization mostly relies on gaining knowledge from others. A new perspective on knowledge acquisition is that individual learning 
should be transformed to organizational learning (Lank, 1997). This will lead to higher organizational performance.

Knowledge acquisition involves the process that actually leads to obtaining of the knowledge. Different terms have been used to refer to the acquisition of knowledge such as acquire, seek, generate, gather, collect, and capture etc. However, all of these terms have common central idea: to accumulate knowledge. Another aspect of knowledge acquisition is innovation, which is the process of creating new knowledge from the application of existing knowledge. Use of existing knowledge in an improved way and effective acquisition of new knowledge is core of the knowledge acquisition process (Inkpen \& Dinur, 1998).

Benchmarking and collaboration are considered to be the most prevalent types of acquisition processes. Benchmarking is a process that involves identifying best practices with in the industry and then assessing the organization's own processes against those standards (O'Dell \& Grayson, 1998). Best practices and difference once identified, the knowledge acquired by organization can be used internally. Creation of new knowledge in an organization basically depends upon the knowledge sharing of personal experiences of employees (Inkpen \& Dinur, 1998).

Collaboration between the individuals leads to knowledge creation. As individual come up with differences such has different cognitive styles, backgrounds, and experiences. These differences can be used to create new knowledge (Leonard, 1995). The basic assumption is that the interaction among the individual employees will foster the learning process and it fosters the process of knowledge socialization (Nonaka \& Takeuchi, 1995). Beyond the collaboration between individual employees, collaboration between organizations also leads to the creation of knowledge (Dyer, 1997; Inkpen \& Dinur, 1998). Pacharapha and Ractham (2012) studied the factors that increase or lessen an individual's tendencies to acquire knowledge from others and found that individual knowledge acquisition is influenced by the recipient's perceived value of knowledge content and knowledge source. Sharing of technology between firms, transfer of employees, alliances, and joint ventures are the different ways that help in acquisition of knowledge in the organizations.

\section{b. Storage}

Once knowledge has been acquired, it must be preserved carefully. Chan (2014) while integrating knowledge management and customer relationship management argued that along with other elements, knowledge storage is key element of knowledge management process. Havens and Knapp (1999) argued that knowledge is created by an organization, thus it is an asset for that organization. Hence disclosure of this knowledge to outside sources should be prohibited. Market value of an organization depends upon the intellectual assets, and attention must be put on an organization's intellectual assets along with the other tangible assets (Du, 2005). To ensure that valued data is kept safe, organization must develop a process of choosing the valuable data and suitable storage for its preservation.

To ensure the protection of data against misuse or illegal practices, many organizations design securityoriented knowledge management processes. To generate and to sustain the competitive advantage, a firm must protect its invaluable knowledge (Porter-Liebskind, 1996). Patents, trademarks, and copyrights are suggested as some of the ways to protect knowledge. But the problem is that all types of knowledge can be defined according to the intellectual property rights and property laws (PorterLiebskind, 1996). Although protecting the knowledge is very difficult, it should not be overlooked. Organizations can take initiatives to protect assets such as job design or employee conduct rules etc. furthermore, organization can rely on the use of technology and software application to limit the access to value knowledge of organization. Extant literature suggests that for an asset to be an actual or potential source of competitive advantage it must be rare and not possible to be easily imitated (Barney, 
1991). Those organizations which lack the security-oriented processes are on the verge of losing vital knowledge and competitive advantage all the time.

\section{c. Application}

Knowledge application involves using the knowledge in performing tasks like problem solving, decision making, new idea generating and learning. Knowledge application is the core task of knowledge management. Nelson and Winter (1982) found that knowledge application is done when an individual person or work unit influences a behavioral change in another unit. An important factor in knowledge transfer is the extent to which an individual not only acquires knowledge from others but also uses that knowledge to perform his/her own tasks (Minbaeva et al., 2003). According to March (1991), best possible treatment of knowledge in an organization requires application of knowledge for the betterment of organization. Application-oriented knowledge management processes are those which are related to the actual utilization of knowledge. However, a little debate has been on the effectiveness of knowledge application in past studies. Most of the studies on the effectiveness of knowledge application were based on assumptions rather on being explicit. Consider for example, it was assumed that once an organization has created the knowledge, it will be applied effectively (Nonaka \& Takeuchi, 1995). Effective application of knowledge helps organizations to improve their efficiency level and reduce their costs.

\subsection{Universities’ performance}

\section{a. Research and productivity}

In the era of knowledge economy, research activities in universities have gained considerable importance (Flagg et al., 2011). It is true that the performance of the faculty has been measured in terms of research output over the years (Burke \& James, 2005). Publications by the faculty have been recognized as a key measure by the accreditation bureaus and academic administration to allow accreditation to continue and assess the qualification of faculty (Koys, 2008). Research output will continue to be the core element in overall performance appraisals of faculty and for the qualification of promotions (Shepherd et al., 2009).

\section{b. Employee commitment}

Employee commitment at work is defined as the psychological attachment sensed by the employee for the organization he/she works for. Employees who are committed to the organization have tendency to believe in and accept the organizational goals and culture. They are loyal with the organization and are motivated to offer best possible services to the organization (Chen, 2007). Studies have shown that those organizations that provide support tend to have more committed employees (Gu \& Siu, 2009). The organizations that invest to develop committed employees have more customer satisfaction (He et al., 2010).Commitment has been found to be significantly related to the employee performance in the existing studies (Chen et al., 2002). Committed employee develops a sense of psychological attachment with the organization which encourages him/her to behave in the manner that is consistent with the organizational goals and objectives. For example, employee commitment was positively related to sales performance of the organization (Farh et al., 1998).

\section{c. Industry linkages}

Recent times have seen more linkage of industries and universities which has changed the role of universities over time. Now universities are more engaged in the technology transfer activities such as technology based venture creation, patents, licenses, consulting and collaborative research (Wright et al., 2008). However, the firms which have profit as a primary objective are different from those of 
universities as they have teaching and research as primary objective (Etzkowitz, 2003). Yet, universityindustry linkages are formed to reap the benefits such as gaining access to the vital knowledge (Caloghirou et al., 2001), enabling problem solving capability (Cohen et al., 2002), development of new technologies by allowing access to new tools and techniques (Rosenberg, 1992), improving firm reputation among potential partners and in labor markets (Hicks,1995), entering in the academic network (Murray, 2002), and escalating opportunities for more public funding (Grimaldi \& von Tunzelmann, 2002).

\subsection{Technology}

\section{a. Technology}

Advent of IT in the recent times has paved a way for many opportunities. Organizations, with high speed internet connection can collect, analyze and share information more easily and effectively. Use of knowledge management system reduces time barriers significantly and dissemination of knowledge more quickly Yao (2007). Hence organizations can respond quickly to the market changes in this dynamic environment. Presence of network and electronic commerce allows for the cooperation among organizations (Mudge, 1999). Universities are at the forefront of using technology in knowledge management practices. Higher education is relying more in virtual education system (Jones \& Pritchard 1999). Universities are now offering online courses for the vast majority of subjects.

Extracted from the earlier literature, Lee and Hong (2002) highlighted four basic steps of knowledge management cycle; knowledge acquisition, knowledge development, knowledge sharing and knowledge application. Technology plays an important part in every step of the knowledge management cycle. For example, information systems can be used for information creation, online data bases for information storing and networks for information sharing. Technology has a significant importance in the overall knowledge management process. The fragmented knowledge in the organization can be integrated through the proper use to information and communication technologies (Argris \& Schon, 1978). Thus barrier to the communication can be driven off that occurs between the different units of an organization. To be successful, an organization must invest in the comprehensive technological infrastructure that can support different types of knowledge and handle communications in difficult situations. On the basis of above construct, the study formulate the following hypothesis i.e.,

H1: knowledge management culture in universities results in high university performance.

H2: Human resources management in universities results in high university performance.

H3: Acquisition of knowledge in universities results in high university performance.

H4: Storage of knowledge in universities results in high university performance.

H5: Application of knowledge in universities results in high university performance.

H6: Technology moderates the influence of knowledge management infrastructure and knowledge management processes on university performance.

H6a: Technology moderates the influence of knowledge management infrastructure on university performance.

H6b: Technology moderates the influence of knowledge management processes on university performance.

\section{Methods}

\subsection{Conceptual framework}

Fig. 1 illustrates the conceptual framework designed for the study. Overall four constructs are used in the study. Model relies on two constructs to measure the university performance i.e. knowledge 
management infrastructure and knowledge management processes. Knowledge management infrastructure is measured using two dimensions (culture and human resources) while knowledge management processes is measured using three dimension (acquisition, storage, and application). In order to measure the construct "universities' performance", we relied on three dimension of performance i.e. research and productivity, employee commitment, and industry linkage. Furthermore, the study also examines the moderating impact of technology on knowledge management infrastructure and knowledge management processes separately and the overall model as a whole.

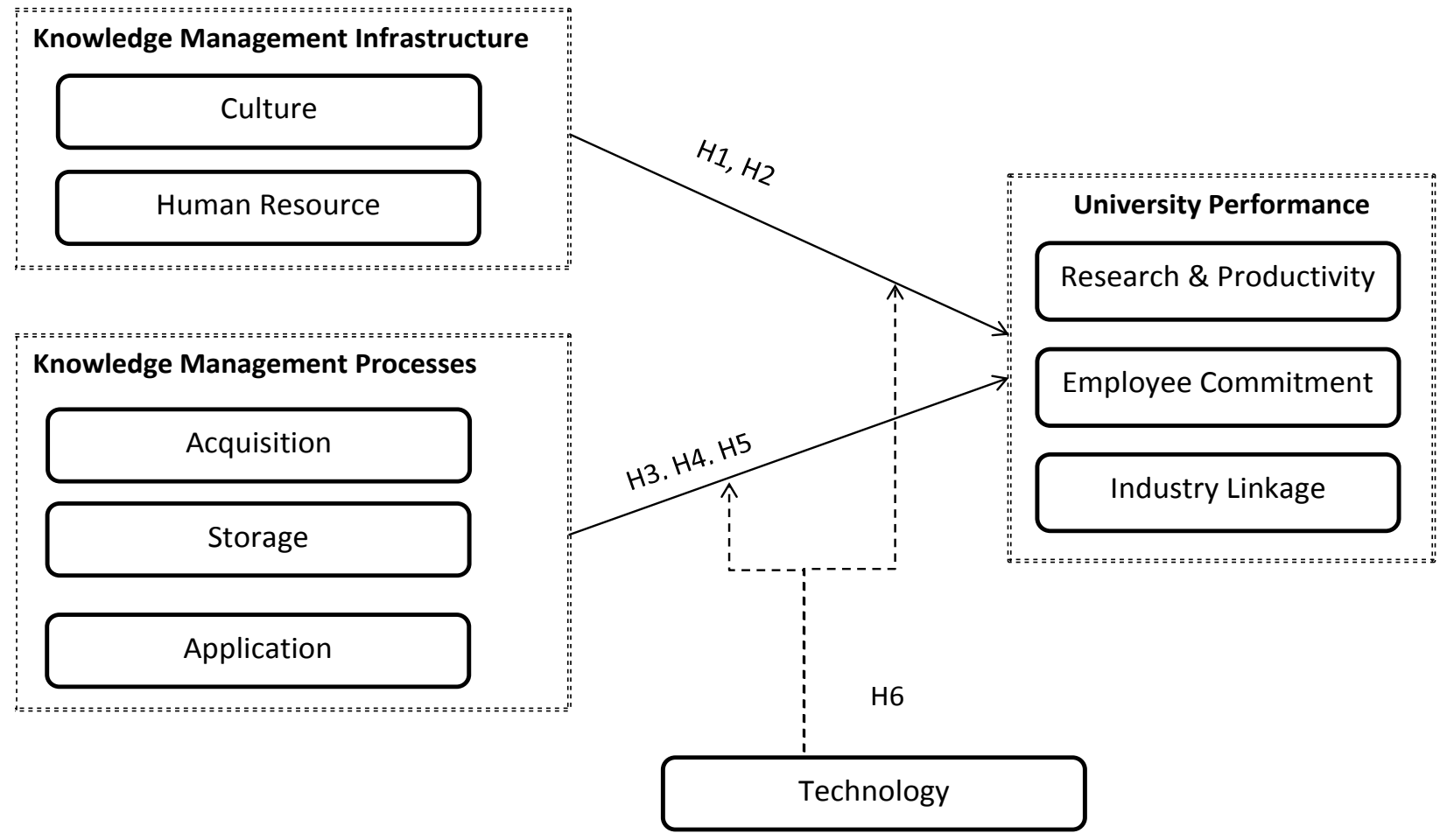

Fig. 1. Conceptual framework (Source: Self constructed)

\subsection{Data collection instrument}

For data collection, a 45 items scale questionnaire was developed and used to elicit the response of target individuals on 5 point Likert scale which is the most prevalently used measure in the scale design. Relevant information was gathered for the variables i.e. knowledge culture, Human resources, knowledge acquisition, knowledge storage, knowledge application, research and productivity, employee commitment, industry linkage, and technology. 11 items were used to measure the construct knowledge management infrastructure, 18 for knowledge management process, 10 for universities' performance and 6 to measure technology.

\subsection{Sample}

A convenient sample of 450 employees from the universities all over the Pakistan was taken for the study. The main reason is to used non-probability sampling technique i.e., convenient sampling is that this sampling technique required relative less cost and less time required which enables to get data relatively fast and inexpensive. In addition, the convenience sample helps to gather useful data and information that would not have been possible using probability sampling techniques, which require more formal access to lists of populations. Hence data was collected from 450 employees' working in the different universities across the Pakistan that represents the sufficient information for the whole population. Demographic statistics for the sample investigated is depicted in the Table 1 for reference. 
Table 1

Demographics

\begin{tabular}{ll}
\hline Gender & Percentage \\
\hline Male & 52.8 \\
Female & 47.2 \\
\hline Job Profile & \\
Teaching & 63 \\
Management & 29 \\
Others & 8 \\
\hline Age & 37 \\
$25-29$ & 46 \\
$30-34$ & 8 \\
$35-39$ & 6 \\
$40-44$ & 3 \\
Above & \\
\hline Provinces & 34 \\
Punjab & 21 \\
Sindh & 11 \\
Baluchistan & 17 \\
Khyber Pakhtoonkhawa (KPK) & 17 \\
\hline Federal & \\
\hline
\end{tabular}

\subsection{Framework construction}

In order to measure the underlying theory, this research relied primarily on multidimensional constructs. Hence for the measurement of various dimensions of constructs, explanatory factor analysis (EFA) was used. Factor analysis is a mechanism which helps to identify the reduced number of variables from the larger number of constructs. In the terminology of factor analysis, the parameters of these factors are known as loadings. The covariance of each pair of variables and the variance of each variable and might be expressed in terms of the loadings. Communality is a part of the variance which is expressed using common factors. The common factors do not account for the specific variance, which is basically a part of variable variance.

\subsubsection{Rotated component analysis}

The varimax rotation method is used for rotated component analysis which encourages the reduced number of factors while discouraging the detection of factors that show influence on all variables. It should be noted however, that interpretation of factors is mostly subjective.

\subsection{EFA results for measurement dimensions of the constructs}

\subsubsection{Construct 1: Knowledge Management Infrastructure}

EFA results for the construct "knowledge management infrastructure" are shown in the table 2. The questions which had loadings less than 0.40 are not included in the further analysis proceedings. Table 2 shows that human resources (HR) and Culture are the two factors that are used in this study to measure knowledge management infrastructure. 11 items (5 HR and 6 Culture) are contributing to the measurement of construct "knowledge management infrastructure". The loadings of majority of the items are more than 0.50 which indicates the more contribution of these factors in the knowledge management infrastructure. Derived from the results of EFA, following dimensions are categorized to measure knowledge management infrastructure. 
Table 2

Rotated component matrix measuring knowledge management infrastructure

\begin{tabular}{|c|c|c|}
\hline Items & HR & Culture \\
\hline Your university offers formal trainings for employees to perform of duties well. & .546 & \\
\hline Your university offers “Job rotation” opportunities for employees to develop themselves. & .912 & \\
\hline Your university staff can perform others’ tasks besides their own tasks. & .586 & \\
\hline Your university staff is specialists in their own part. & .848 & \\
\hline Environmental changes do not hinder the performance of employees. & .586 & \\
\hline There is a willingness to collaborate across department within your university. & & .575 \\
\hline Your university staff is helpful. & & .516 \\
\hline Your university staff is generally trustworthy. & & .466 \\
\hline Your university staff has faith on each other's behaviors & & .887 \\
\hline Your university staff can communicate easily with other departments' staff besides their own & & .629 \\
\hline Your university staff is supportive for knowledge sharing \& creation. & & .541 \\
\hline
\end{tabular}

\subsubsection{Construct 2: Knowledge management processes}

Table 3 shows that the construct "Knowledge management processes" comprises three factors viz. knowledge acquisition, storage and application. Acquisition comprises 6 factors, storage consists of 7 factors while application comprises 5 factors. All the 18 items are having maximum contribution in the component "Knowledge management processes" and the loading are more than 0.50 in majority of cases.

\section{Table 3}

Rotated component matrix measuring knowledge processes

\begin{tabular}{llll}
\hline Items & Acquisition & Storage & Application \\
\hline Your university acquires prior information about the students. & .539 & \\
Your university has processes for modifying existing knowledge. & .576 & .499 & .851 \\
Your university uses feedback from faculty to evaluate students. & .611 & .608 & \\
Your university uses feedback from students to assess education & & .540 \\
Your university has processes for acquiring knowledge about other & .757 \\
Your university has processes to share knowledge between & .751 \\
Your university appreciates storage of knowledge in databases, & .425 \\
You can easily find the exact knowledge that you need. & .608 \\
You have easy access to knowledge that enables you to do your tasks. & .816 \\
Experts have that specific knowledge that you need. & .444 \\
The specific knowledge that you need is stored at an online portal. & \\
The knowledge stored at the portal requires lot of modifications before & & \\
Updated and relevant knowledge is stored in your university & & .512 \\
Your university has processes that facilitate the application of & & .578 \\
There are processes that allows for the application of knowledge learnt & & .517 \\
Your university has processes for using knowledge to tackle new & & .654 \\
\hline There is use of knowledge for the improvement of overall efficiency in & \\
Application of knowledge at your university is quick when it is related & & \\
\hline
\end{tabular}

\subsubsection{Construct 3: Universities’ performance}

Table 4 shows the three components of universities' performance i.e. research and productivity (R\&P), employee's commitment (EMP), and industry linkages (IL). A total of 10 items were used to measure the construct and maximum contribution in the universities' performance was shown by the factors. There were 4 items regarding research and productivity, 3 about employee's commitment and 3 were about industry linkages of the university. All the items had loadings above 0.50 .Derived from the results of EFA, following dimensions are categorized to measure universities’ performance. 
Table 4

Rotated component matrix measuring universities’ performance

\begin{tabular}{lcc}
\hline Items & R\&P & EMP \\
\hline Your university ranks high on HEC list. & .781 & IL \\
Your university focuses on quality of research. & .883 & .758 \\
Your university allows faculty to seek higher education. & .800 & .602 \\
Your university facilitates faculty to improve their qualification. & .502 \\
Employee loyalty in your university is at high level. & .681 \\
Your university staff is helpful and trustworthy. & .647 \\
Employees feel very committed to the university. & .581 \\
Your university has close link with industry. & .710 \\
Your university is providing solutions to industrial problems. & \\
University provides training to industrial professionals. & \\
\hline
\end{tabular}

\subsubsection{Construct 4: Technology}

Table 5 lists loadings and items used to measure the technology. It is depicted that 6 items were used to measure the technology and all had loadings above 0.50 .

Table 5

Rotated component matrix measuring technology

\begin{tabular}{ll}
\hline Items & IT \\
\hline Your university facilitates with IT support at any time and place when it comes to collaborative works. & .703 \\
Your university offers IT support to the staff for communication with each other. & .763 \\
You can easily access the job related information via computer. & .870 \\
Your university provides with groupware facility for information acquisition. & .693 \\
You have intranet facility at your university for information sharing & .670 \\
There is an IT support for proper storing of data at your university & .841 \\
\hline
\end{tabular}

\section{Results}

\subsection{Correlation analysis and reliability}

Correlation analysis is performed to test the strength and direction of the relationship between the variables. Table 6 shows the correlation and reliabilities of technology (IT), human resources (HR), culture (CLT), acquisition (ACQ), storage (STR), application (APP), research and productivity (R\&P), employee commitment (EMP) and industry linkages (IL). To measure the internal consistency of the items of scale, Cronbach's alpha was calculated. According to George and Mallery (2003) provide the following rules of thumb: " $\alpha>.9$ indicates Excellent, $\alpha>.8$ indicates Good, $\alpha>.7$ indicates Acceptable, $\alpha>.6$ indicates Questionable, $\alpha>.5$ indicates Poor, and $\alpha<.5$ indicates Unacceptable". All the variables have alpha value above 0.70 which indicates the good internal consistency of among the items.

Table 6

Correlation matrix and reliability

\begin{tabular}{ccccccccccc}
\hline \multicolumn{1}{c}{} & $\alpha$ & IT & HR & CLT & ACQ & STR & APP & R\&P & EMP & IL \\
\hline IT & .741 & 1 & $.432^{* *}$ & .297 & $.537^{* *}$ & $.654^{* *}$ & $.446^{* *}$ & .293 & .109 & .219 \\
HR & .705 & $.432^{* *}$ & 1 & $.510^{* *}$ & $.410^{* *}$ & $.734^{* *}$ & $.707^{* *}$ & .211 & .037 & .214 \\
CLT & .730 & .297 & $.510^{* *}$ & 1 & $.673^{* *}$ & $.557^{* *}$ & $.503^{* *}$ & .175 & $.455^{* *}$ & .182 \\
ACQ & .766 & $.537^{* *}$ & $.410^{* *}$ & $.673^{* *}$ & 1 & $.750^{* *}$ & $.617^{* *}$ & .307 & $.535^{* *}$ & $.455^{* *}$ \\
STR & .757 & $.654^{* *}$ & $.734^{* *}$ & $.557^{* *}$ & $.750^{* *}$ & 1 & $.612^{* *}$ & $.313^{*}$ & .214 & $.370^{*}$ \\
APP & .808 & $.446^{* *}$ & $.707^{* *}$ & $.503^{* *}$ & $.617^{* *}$ & $.612^{* *}$ & 1 & $.314^{*}$ & $.445^{* *}$ & $.556^{* *}$ \\
R\&P & .234 & .293 & .211 & .175 & .307 & $.313^{*}$ & $.314^{*}$ & 1 & .181 & .210 \\
EMP & .762 & .109 & .037 & $.455^{* *}$ & $.535^{* *}$ & .214 & $.445^{* *}$ & .181 & 1 & $.644^{* *}$ \\
IL & .837 & .219 & .214 & .182 & $.455^{* *}$ & $.370^{*}$ & $.556^{* *}$ & .210 & $.644^{* *}$ & 1 \\
\hline
\end{tabular}

Note: $* *$ represents significant at $5 \%$ level. 


\subsection{Regression analysis}

Ordinary least square (OLS) regression was used to perform the analysis of hypothesis set forth. For the analysis of data IBM SPSS Statistics 20 was used. A significant positive relationship was expected between human resources (HR) and university performance. The results showed that that human resources (HR) had a significant positive influence on universities' performance $(b=1.417)$. Hence the $\mathrm{H} 1$ was supported with the results. Table 7 shows the output of regression analysis.

We posited in $\mathrm{H} 2$ that knowledge management culture will result in higher university performance. The results revealed that the organizations which foster knowledge management culture lead to better university performance $(b=0.023)$.

Our H3 was also supported by the analysis that acquisition of knowledge results in higher university performance. The results revealed that knowledge acquisition has a significant positive effect on universities’ performance ( $\mathrm{b}=0.667$ and $\mathrm{p}<0.001)$.

The assumption that university which stores and protects data their knowledge will have higher performance was supported by the data. Hence $\mathrm{H} 4$ was supported and storage showed significant positive relationship with the university performance ( $b=0.636$ and $p<0.05$ ).

The study also revealed that not only the acquisition and storage of precious knowledge but also the application of that knowledge is vital for the higher performance of universities. Thus our H5 was also supported and results showed that knowledge application with $b=1.862$ was positive and significant predictor of universities’ performance.

\section{Table 7}

Regression analysis

\begin{tabular}{lcccc}
\hline & $\mathrm{B}$ & $\mathrm{Std}$. Error & $\mathrm{t}$ & Sig. \\
\hline (Constant) & .493 & 1.399 & .352 & .407 \\
HR & 1.417 & .587 & 2.414 & .000 \\
Culture & .023 & .484 & .047 & .001 \\
Acquisition & .447 & .670 & .667 & .000 \\
Storage & .636 & .830 & .766 & .003 \\
Application & 1.862 & .497 & 3.745 & .000 \\
Diagnostic Statistics & $\mathrm{R}$ & $\mathrm{R}^{2}$ & Adjusted R & Std. Error \\
& .752 & .565 & .505 & 1.27874 \\
\hline
\end{tabular}

Dependent variable: University performance

\subsection{Moderating effect of technology}

In our H6 we hypothesized that technology moderates the influence of knowledge management infrastructure and knowledge management processes on university performance. Furthermore, we also tested for the moderating effect of technology on knowledge management infrastructure (H6a) and knowledge management processes (H6b) on university performance independently. In order to test the moderating effect of technology on the relationship with university performance, we used a two-step hierarchical multiple regression as recommended by Cohen et al. (2003). The first step involves regression of dependent variable upon the predictor and moderating variables. In the second step scores obtained from the multiplication of variables used in first step are multiplied to create an interaction term. Then this interaction term is included in the regression model. However, this may arouse the problem of multicollinearity in the study due to high correlation between the variables in the first model and the interaction term. To overcome the multicollinearity issue, variables are centered prior to multiplying. The moderation is assumed to exist when the regression coefficient associated with the interaction term is significant. 
Table 8 presents the results of hierarchical multiple regression. It is revealed that technology moderates the relationship between knowledge management infrastructure (KMI) and university performance ( $\beta$ $=0.131$ ). Thus our hypothesis H6a is supported.

\section{Table 8}

Moderating effect of technology

\begin{tabular}{llllll}
\hline Model & $\beta$ & $\mathrm{SE} \beta$ & $\beta^{\mathrm{a}}$ & $\Delta^{2}$ & VIF \\
\hline Dependent Variable: Universities' Performance (H6a) & & & & & \\
\hline Step 1: & & & & & \\
Knowledge management infrastructure (KMI) & 0.441 & 0.040 & 0.578 & & 1.39 \\
Technology & 0.288 & .081 & 0.189 & & 1.39 \\
\hline Step 2: & & & & & \\
KMI*Technology & 0.141 & 0.057 & 0.131 & 0.021 & 1.14
\end{tabular}

Dependent Variable: Universities’ Performance(H6b)

\begin{tabular}{llllll}
\hline Step 1: & & & & & \\
Knowledge management processes (KMP) & 0.411 & 0.064 & 0.483 & 1.28 \\
Technology & 0.149 & 0.115 & 0.080 & 1.28 \\
\hline Step 2: & & & & & \\
KMP *Technology & 0.017 & 0.078 & 0.019 & 0.017 & 1.13 \\
\hline
\end{tabular}

Dependent Variable: Universities’ Performance(H6)

\begin{tabular}{|c|c|c|c|c|c|}
\hline \multicolumn{6}{|l|}{ Step 1: } \\
\hline KMD & 0.414 & 0.055 & 0.482 & & 1.41 \\
\hline Technology & 0.099 & 0.056 & 0.101 & & 1.41 \\
\hline \multicolumn{6}{|l|}{ Step 2: } \\
\hline KMI * KMP *Technology & 0.060 & 0.031 & 0.109 & 0.019 & 1.17 \\
\hline
\end{tabular}

Concerning the moderating effect on relationship between knowledge management processes (KMP) and university performance, Table 8 elaborates that relationship is moderated by technology $(\beta=0$ .019). These results support H6b. At third stage the moderating effect of technology was tested with overall model. The results revealed that technology moderates the relationship of knowledge management dimensions (KMD) and university performance $(\beta=0.109)$.

\section{Conclusion}

This study investigated the relationship between knowledge management practices and universities' performance in the context of Pakistan. The study measured the dimensions of knowledge management and organizational performance in Pakistani universities. The results showed that two dimensions (culture and human resources) of knowledge management infrastructure and three dimensions (acquisition, storage, and application) of knowledge management processes significantly predicted the university performance. Thus it is concluded that those universities which indulge in proper knowledge management practices and consider it one of the most important tools, are destined to success.

In addition, the study found that besides the important role played by knowledge management dimensions in enhancing the performance of universities; technology played a significant moderating role in the overall process. Extracted from the earlier literature it was also found that technology plays an important part in every step of the knowledge management cycle (Lee \& Hong, 2002). Among the four pillars of knowledge management i.e. organization, learning, leadership, and technology presented by Stankosky and Baldanza (2000), technology was deemed to be the most vital one. The study concludes that in order to be among the top performers in the era of information, universities should 
accept, adopt and consistently foster their knowledge management practices. Universities have to provide platform for the knowledge management practices by developing the culture and motivating the human element. Once the platform is there, knowledge acquisition, storage and application becomes inevitable. In the entire process, it should not be forgotten that technology leads the way towards achieving the higher overall performance in the utilization of knowledge management practices.

\section{Implications}

Findings of this study have valuable theoretical and practical implications. Theoretically, adds to the extant literature as numerous studies have been conducted on the impact of knowledge management in the context of corporations in past. However, the numbers of studies in the education sector were still limited, and specifically in context of Pakistan. For an academic, this study will provide a valuable source of support for knowledge management practices and conceptualization in universities of Pakistan. To the practitioners, this study not only provides an empirical model on the knowledge management practices in a developing economy, but also a source of knowledge revealing the most important factors in enhancing the universities' performance. For example, HR and application of knowledge were most important factors amongst the discussed. Hence, those universities, which will encourage their employees to get involved in the sharing of knowledge and apply their knowledge, will be better off than the rest.

\section{References}

Allen, P. (1988). Missions of Colleges and Universities. San Francisco: Jossey.

Argyris, C., \& Schon, D. (1978). Organizational learning: A theory of action approach. Reading, MA: Addision Wesley.

Barney, J. (1991). Firm resources and sustained competitive advantage. Journal of management, 17(1), 99-120.

Betz, F. (2014). Control in knowledge economies. Journal of the Knowledge Economy, 5(4), 761-783.

Betz, F., Min, W., \& Shin, D. W. (2014). Universities and Entrepreneurship in Asia: The Case of Nano. Journal of the Knowledge Economy, 5(4), 803-819.

Bock, G.-W., Zmud, R. W., Kim, Y.-G., \& Lee, J.-N. (2005). Behavioral intention formation in knowledge sharing: Examining the roles of extrinsic motivators, social-psychological forces, and organizational climate. Mis Quarterly, 87-111.

Burke, L. A., \& James, K. E. (2005). An empirical investigation of faculty research productivity and implications for practice. International Journal of Management Practice, 1(2), 109-130.

Caloghirou, Y., Tsakanikas, A., \& Vonortas, N. S. (2001). University-industry cooperation in the context of the European framework programmes. The Journal of Technology Transfer, 26(1-2), 153161.

Chan, J. O. (2014). Integrating knowledge management and relationship management in an enterprise environment. Communications of the IIMA, 9(4), 4.

Chang, T.-C., \& Chuang, S.-H. Performance implications of knowledge management processes: Examining the roles of infrastructure capability and business strategy. Expert systems with applications, 38(5), 6170-6178.

Chen, Y.-J. (2007). Relationships among service orientation, job satisfaction, and organizational commitment in the international tourist hotel industry. Journal of American Academy of Business, 11(2), 71-82.

Chen, Z. X., Tsui, A. S., \& Farh, J. L. (2002). Loyalty to supervisor vs. organizational commitment: Relationships to employee performance in China. Journal of Occupational and Organizational Psychology, 75(3), 339-356.

Cohen, W. M., Nelson, R. R., \& Walsh, J. P. (2002). Links and impacts: the influence of public research on industrial R\&D. Management science, 48(1), 1-23.

Davenport, T. H., \& Klahr, P. (1998). Managing customer support knowledge. California management 
review, 40, 195-208.

Drucker, P. F. (1994). Post-capitalist society: HarperCollins.

Du Plessis, M. (2005). Drivers of knowledge management in the corporate environment. International journal of information management, 25(3), 193-202.

Dyer, J. (2002). Effective interfirm collaboration: how firms minimize transaction costs and maximize transaction value.

Etzkowitz, H. (2003). Research groups as â€ quasi-firmsâ€тм: the invention of the entrepreneurial university. Research Policy, 32(1), 109-121.

Farh, J.-L., Tsui, A. S., Xin, K., \& Cheng, B.-S. (1998). The influence of relational demography and guanxi: The Chinese case. Organization Science, 9(4), 471-488.

Firestone, J. M., \& McElroy, M. W. (2003). Key issues in the new knowledge management: Routledge.

Flagg, D., Gilley, O. W., \& Park, J. C. (2011). Job Market Signaling: What Drives the Productivity of Finance Ph. Ds? Financial Management, 40(2), 483-513.

George, D., \& Mallery, M. (2003). Using SPSS for Windows step by step: a simple guide and reference. Boston, MA: Allyn y Bacon.[Links].

Gholipour, R., Jandaghi, G., \& Hosseinzadeh, S. A. A. Explanation of knowledge management enabler as a latent variable: A case study of SMEs in Iran. Afr. J. Bus. Manage, 4(9), 1863-1872.

Gold, A. H., Malhotra, A., \& Segars, A. H. (2001). Knowledge management: an organizational capabilities perspective. J. of Management Information Systems, 18(1), 185-214.

Grimaldi, R., \& Von Tunzelmann, N. (2002). Assessing collaborative, pre-competitive R\&D projects: the case of the UK LINK scheme. R\&D Management, 32(2), 165-173.

Gu, Z., \& Chi Sen Siu, R. (2009). Drivers of job satisfaction as related to work performance in Macao casino hotels: An investigation based on employee survey. International Journal of Contemporary Hospitality Management, 21(5), 561-578.

He, Y., Li, W., \& Keung Lai, K. (2011). Service climate, employee commitment and customer satisfaction: evidence from the hospitality industry in China. International Journal of Contemporary Hospitality Management, 23(5), 592-607.

Hellström, T., \& Husted, K. (2004). Mapping knowledge and intellectual capital in academic environments: A focus group study. Journal of Intellectual Capital, 5(1), 165-180.

Hicks, D. (1995). Published papers, tacit competencies and corporate management of the public/private character of knowledge. Industrial and corporate change, 4(2), 401-424.

Inkpen, A. C., \& Dinur, A. (1998). Knowledge management processes and international joint ventures. Organization Science, 9(4), 454-468.

Jones, D. R., \& Pritchard, A. (1999). Realizing the Virtual University. Educational Technology, 39(5), 56-60.

King, W. R. (2008). Questioning the conventional wisdom: culture-knowledge management relationships. Journal of Knowledge Management, 12(3), 35-47.

King, W. R. (2009). Knowledge management and organizational learning: Springer.

Koys, D. J. (2008). Judging academic qualifications, professional qualifications, and participation of faculty using AACSB guidelines. Journal of Education for Business, 83(4), 207-213.

Lank, E. (1997). Leveraging invisible assets: the human factor. Long Range Planning, 30(3), 406-412.

Lee, H., \& Choi, B. (2003). Knowledge management enablers, processes, and organizational performance: an integrative view and empirical examination. Journal of management information systems, 20(1), 179-228.

Lee, S., Gon Kim, B., \& Kim, H. (2012). An integrated view of knowledge management for performance. Journal of Knowledge Management, 16(2), 183-203.

Lee, S. M., \& Hong, S. (2002). An enterprise-wide knowledge management system infrastructure. Industrial Management \& Data Systems, 102(1), 17-25.

Leonard, D., \& Sensiper, S. (1998). The role of tacit knowledge in group innovation. California management review, 40(3), 113.

Leonard-Barton, D. (1995). Wellsprings of knowledge: Building and sustaining the sources of innovation: Harvard Business Press. 
Levinthal, D. A., \& March, J. G. (1993). The myopia of learning. Strategic management journal, 14(S2), 95-112.

Liao, S.-H., Wu, C.-C., Hu, D.-C., \& Tsuei, G. A. (2009). Knowledge acquisition, absorptive capacity, and innovation capability: an empirical study of Taiwan's knowledge-intensive industries. technology, 11, 13.

Liebeskind, J. P. (1996). Knowledge, strategy, and the theory of the firm. Strategic management journal, 17(S2), 93-107.

Loh, B., Tang, A.-C., Menkhoff, T., Chay, Y. W., \& Evers, H.-D. (2003). Applying knowledge management in university research.

March, J. G. (1991). Exploration and exploitation in organizational learning. Organization Science, 2(1), 71-87.

Meihami, B., \& Meihami, H. (2014). Knowledge Management a way to gain a competitive advantage in firms (evidence of manufacturing companies). International Letters of Social and Humanistic Sciences(03), 80-91.

Mills, A. M., \& Smith, T. A. Knowledge management and organizational performance: a decomposed view. Journal of Knowledge Management, 15(1), 156-171.

Minbaeva, D., Pedersen, T., Björkman, I., Fey, C. F., \& Park, H. J. (2003). MNC knowledge transfer, subsidiary absorptive capacity, and HRM. Journal of international business studies, 34(6), 586-599.

Moss Kanter, R., Stein, B. A., \& Jick, T. D. (1992). The challenge of organizational change: How companies experience it and leaders guide it. New York.

Mudge, A. (1999). Knowledge Management: Do We Know That We Know? COMMUNICATION WORLD-SAN FRANCISCO-, 16, 25-27.

Murray, F. (2002). Innovation as co-evolution of scientific and technological networks: exploring tissue engineering. Research Policy, 31(8), 1389-1403.

Nelson, R. R., \& Winter, S. G. (2002). Evolutionary theorizing in economics. The journal of economic perspectives, 16(2), 23-46.

Nidumolu, S. R., Subramani, M., \& Aldrich, A. (2001). Situated learning and the situated knowledge web: Exploring the ground beneath knowledge management. Journal of management information systems, 18(1), 115-150.

Nonaka, I. (1994). A dynamic theory of organizational knowledge creation. Organization Science, 5(1), 14-37.

Nonaka, I., \& Konno, N. (2005). THE CONCEPT OF" 5, 4": BUILDING A FOUNDATION FOR KNOWLEDGE CREATION. Knowledge management: critical perspectives on business and management, 2(3), 53.

Nonaka, I., \& Takeuchi, H. (1995). The knowledge-creating company: How Japanese companies foster creativity and innovation for competitive advantage. London ua.

Nonaka, I., \& Takeuchi, H. (1996). The knowledge-creating company: How Japanese companies create the dynamics of innovation. Long Range Planning, 29(4), 592.

Oâ€ ${ }^{\mathrm{TM}}$ Dell, C., \& Grayson, C. J. (1998). If only we knew what we know. California management review, 40(3), 154-174.

Oliver, S., \& Kandadi, K. R. (2006). How to develop knowledge culture in organizations? A multiple case study of large distributed organizations. Journal of Knowledge Management, 10(4), 6-24.

Pacharapha, T., \& Vathanophas Ractham, V. (2012). Knowledge acquisition: the roles of perceived value of knowledge content and source. Journal of Knowledge Management, 16(5), 724-739.

Pandey, S. C., \& Dutta, A. (2013). Role of knowledge infrastructure capabilities in knowledge management. Journal of Knowledge Management, 17(3), 435-453.

Quink, U. (2008). An exploration of knowledge management and intellectual capital in a nonprofit organisation context.

Quinn, J. B. (1992). Intelligent Enterprise: A Knowledge and Service Based Paradigm for Industr: Simon and Schuster.

Rosenberg, N. (1992). Scientific instrumentation and university research. Research Policy, 21(4), 381390. 
Ryu, C., Kim, Y. J., Chaudhury, A., \& Rao, H. R. (2005). Knowledge acquisition via three learning processes in enterprise information portals: learning-by-investment, learning-by-doing, and learning-from-others. Mis Quarterly, 29(2), 245-278.

Shepherd, C. D., Carley, S. S., \& Stuart, R. S. (2009). An Exploratory Investigation of the Periodic Performance Evaluation Processes for Marketing Faculty A Comparison of Doctoral-Granting and Non-Doctoral-Granting Universities. Journal of Marketing Education, 31(2), 143-153.

Shoham, S., \& Perry, M. (2009). Knowledge management as a mechanism for technological and organizational change management in Israeli universities. Higher education, 57(2), 227-246.

Soliman, F., \& Spooner, K. (2000). Strategies for implementing knowledge management: role of human resources management. Journal of Knowledge Management, 4(4), 337-345.

Stacey, R. (2003). Complex responsive processes in organizations: Learning and knowledge creation: Routledge.

Stankosky, M. A., \& Baldanza, C. (2000). Knowledge management: an evolutionary Architecture Toward enterprise engineering. International Council on Systems Engineering (INCOSE), Reston, $V A$.

Von Krogh, G. (1998). Care in. California management review, 40(3), 133.

Winston, G. C. (1997). Why can't a college be more like a firm. Change: The Magazine of Higher Learning, 29(5), 32-38.

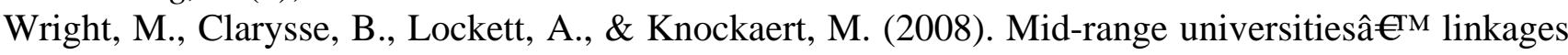
with industry: Knowledge types and the role of intermediaries. Research Policy, 37(8), 1205-1223.

Wu, H.-H. (2004). Mechanism and Cultural Perspectives of Knowledge Management: Model Construction and An Empirical Survey Linking with Knowledge Strategy and Performance. The Postgraduate Programs in Management of The I-Shou University. Masterâ€ ${ }^{\mathrm{TM}_{\mathrm{S}}}$ Thesis.

Yao, H.-Y. (2007). An Exploratory Study of Knowledge Management Systems for Mid-Level Management Decision Making. The Department and Graduate Program of Information and Communications at Shih Hsin University Masterâ€ $€^{\mathrm{TM}_{S}}$ Thesis.

Zaied, A. N. H., Hussein, G. S., \& Hassan, M. M. The Role of Knowledge Management in Enhancing Organizational Performance. International Journal of Information Engineering and Electronic Business (IJIEEB), 4(5), 27. 